\title{
УСПЕХ КАК ЭКЗИСТЕНЦИАЛ БЫТИЯ ЧЕЛОВЕКА
}

\section{В.С. Писчиков, М.М. Холин}

В человеческой жизни, даже на уровне обыденного восприятия, выделяются особые состояния, в которых наиболее полно и адекватно выражается ее суть, вокруг которых концентрируются все другие ее проявления. Эти состояния можно назвать экзистенциалами ${ }^{1}$ бытия человека. Несмотря на изменчивость, многообразие и разнообразие форм жизни, обусловленные социокультурными, временными, индивидуально-личностными и другими обстоятельствами, экзистенциалы выступают как своего рода бытийные инварианты. K ним относятся любовь и ненависть, дружба и вражда, счастье и несчастье, радость и печаль, страдание, одиночество, отчуждение, страх, жизнь и смерть и др. Хотя говорить о полноте/неполноте этого ряда в принципе неправомерно, но, как нам представляется, в нем все же недостает, по крайней мере, еще одного экзистенциала-успеха. Однако в данном качестве в соответствующей литературе он не только не рассматривается, но даже не упоминается, хотя, на наш взгляд, все необходимые основания для этого есть.

Наиболее вероятной причиной такого невнимания исследователей может быть то обстоятельство, что в качестве жизненной реалии бытия современного человека успех дискредитирован своей неразрывной связью с потребительством как образом жизни и системой ценностей. Безусловно, подобного рода связь отрицать не приходится,

\footnotetext{
1 Этот термин, как правило, и вполне обоснованно, ассоциируется с экзистенциальной философией. Однако в статье он употребляется исключительно в отмеченном здесь более широком значении и не несет специфических для данной философии смысловых оттенков.
} 
но было бы ошибочным универсализировать ее, рассматривая как сущностную, а не конкретно-историческую, обусловленную особенностями современного социума как общества потребления. Напротив, в качестве жизненной реалии и ценности успех всегда был, есть и будет необходимым, важнейшим компонентом человеческого бытия, его экзистенциалом. Раскрытию и обоснованию этой мысли и посвящена статья.

Исходным в осмыслении успеха как бытийного феномена является рассмотрение его в контексте деятельности и вообще активности субъекта, где он предстает в качестве результата. Поскольку же субъект всегда ориентирован на достижение позитивного результата, то и любой успех обладает качеством позитивности. Чаще всего он связывается с осуществлением поставленной цели. Однако связь эта не является ни необходимой, ни однозначной. Поэтому нередко возникают определенные трудности в оценке деятельности субъекта как успешной или не успешной. Это относится прежде всего к тем ситуациям, в которых позитивность результата является следствием не достижения поставленной цели, а влияния непредусмотренных субъектом побочных, иногда случайных, факторов. Причем этот непредусмотренный позитивный смысл иногда может превосходить по своей значимости для самого субъекта (или других) ожидавшийся гипотетический результат (такова судьба многих выдающихся открытий в науке, да и жизненных успехов).

В случаях подобного рода комплексный результат деятельности, безусловно, является неоднозначным, противоречивым, и речь при его оценке может идти лишь о доминанте его содержания - позитивной (успех) или негативной (неудача). Возможны также ситуации, когда успех, являясь реализацией поставленной субъектом цели, не во всем адекватен ей, в том смысле, что корректируя и дополняя ее, выходит за ее границы, перекрывает ее содержательно. Могут быть и иные формы неадекватности успеха как результата поставленной субъектом цели.

Отмеченные здесь неоднозначности в оценке результата деятельности субъекта как успеха/неудачи свидетельствуют о творческом характере, сложности и противоречивости целеполагающей деятельности человека, но также и о сложности социального контекста ее осуществления. Безусловно и однозначно одно: успех всегда предстает как объективно фиксируемый результат деятельности (активности) субъекта, позитивный для него или других по своей значимости, а деятельность в целом любого субъекта (будь то социум или отдельный индивид) немыслима без успеха, который с необходимостью присутствует в ней, 
благодаря которому она осуществляется. Речь при этом идет не только о трудовой деятельности человека, но и любой другой форме его активности во всех ее разнообразных проявлениях. Все это и является основанием характеризовать успех, рассматриваемый в объективном его измерении, как сущностный феномен человеческого бытия.

В своем субъективном измерении успех предстает прежде всего как один из важнейших способов самореализации индивида как личности, в ходе которой в той или иной мере осуществляется опредмечивание ее возможностей. В объективированной, т.е. предельно очевидной и достоверной форме, в успехе не только перед самим индивидом, но и перед другими предстают в качестве уже осуществившихся его способности и возможности, которые до этого существовали в нем лишь как потенции, включая и те, что пребывали за горизонтом его сознания. С этой стороны успех выступает также и в качестве активного способа самопознания личности. Он вызывает позитивную самооценку личности и сопровождается специфическим психологическим и ментальным состоянием: уверенностью в себе и самоуважением, приливом жизненной энергии и воодушевлением, оптимизмом и другими чувствами и эмоциями.

В самореализации личности как процессе целесообразно различать два качественно и функционально не всегда совпадающих аспекта самоосуществление (включая самовыражение) и самоутверждение. Доминантой самоосуществления личности является максимально адекватная реализация поставленной ею цели в соответствии с природой и внутренней логикой деятельности, которую она осуществляет. В этом смысле самоосуществление является по преимуществу внутренней, обусловленной возможностями и ценностями самой личности, стороной успеха. Самоутверждение же, напротив, - это по преимуществу внешняя, ориентированная вовне, на других, социальная по своей интенции, сторона успешной самореализации личности. Ее доминантой является вхождение личности как субъекта в контекст межличностных и более широких отношений и связей с целью занять в них подобающее ей, достойное (в ее понимании) место - положение, статус, роль и др.

Самоосуществление личности и ее самоутверждение как стороны самореализации, ведущей к успеху, органично взаимосвязаны. Поскольку самоосуществление личности по необходимости происходит в более или менее широком пространстве межличностной коммуникации и социальных связей, то оно неизбежно, даже не зависимо от намерений личности приобретает и характер ее самоутверждения. 
В то же время самоутверждение, если оно достигается посредством должного отношения к выполняемой личностью деятельности, принимает одновременно и характер самоосуществления и саморазвития личности.

Однако отнюдь не всегда связь между этими двумя сторонами самореализации личности является естественной и органичной, она может приобретать и иной характер - рассогласованности и даже взаимоисключения. Это происходит, в частности, в том случае когда у личности сформировалась неадекватная Я-концепция. У личности со слабой Я-концепцией, основанной прежде всего на заниженной самооценке, успехи в самоосуществлении могут и не стать основой для адекватных успехов в самоутверждении. И наоборот, личность, обладающая сильной Я-концепцией, завышенной самооценкой и недостаточно развитой морально-этической мотивацией, может добиться желаемых успехов в самоутверждении внешними по отношению к своей деятельности путями и способами. В данном случае успех как инструмент самоутверждения личности не только отрывается от естественного ее самоосуществления и саморазвития, но и противопоставляется им. Именно о такой ситуации в творческой самореализации в искусстве писал Б. Пастернак в своем известном стихотворении «Быть знаменитым некрасиво»:

Цель творчества - самоотдача,

А не шумиха, не успех.

Позорно, ничего не знача,

Быть притчей на устах у всех.

Таким образом, в своем субъективном измерении успех выступает как форма и способ самореализации (самоосуществления и самоутверждения), самопознания и саморазвития личности, в чем проявляется творчески активная сущность человека как всесторонне осваивающего мир социоприродного существа. Потому не только в объективном, но и субъективном измерении, то есть в своей целостности, успех выступает в качестве бытийного феномена - экзистенциала человеческого бытия.

Такое понимание природы успеха и его роли в бытии человека означает, что он присутствует в повседневной жизни каждой (психически нормальной и дееспособной) личности как позитивное завершение разнообразных ее дел и действий, разрешение простых и сложных житейских проблем, преодоление многочисленных препятствий и трудностей. Но существует ли тогда смысл в широко используемых не только 
в повседневной жизни, но и в научной лексике (прежде всего психологической), понятиях «успешная/неуспешная личность»? Эти понятия, на наш взгляд, имеют ограниченный смысл - как обозначения индивидуальных различий между личностями в том, каково соотношение в их жизни либо определенном виде деятельности успехов и неудач. При этом берутся в расчет не все, а лишь жизненно или профессионально значимые, заметные успехи и неудачи (общего же их баланса не знает никто, включая и саму личность).

Череда жизненно значимых успехов личности формирует у нее представление о неслучайном их характере и как следствие - образ-Я успешной личности. Осознание же успешности формирует у индивида представление о своей состоятельности, самодостаточности, что укрепляет уверенность личности в своих возможностях и силах и, в свою очередь, способствует дальнейшей ее успешности: так между этими качествами личности устанавливаются отношения взаимообусловленности.

Понимание природы успеха не может быть адекватным без выявления обусловливающих его разнообразных по своей природе и происхождению факторов. Безусловно, среди них прежде всего логично назвать индивидуально-личностные качества человека, начиная с его природных характеристик (генетически обусловленных и приобретенных) и заканчивая комплексом его личностных качеств. Все они в той иной мере, потенциально или актуально способствуют успеху или затрудняют его. Особенно значимы среди них такие индивидуальные качества, которые непосредственно, актуально влияют на успех. Их совокупность весьма удачно, на наш взгляд, некоторые психологи называют «жизненным ресурсом личности», представляющим собой «сложноорганизованный (имеющий определенную величину, структуру и динамику) источник силы человека, поддерживающий обеспечение жизненной активности на определенном уровне, зависящем от его актуальных возможностей» $[2$, с. 8]. Функционально жизненный ресурс личности, рассматриваемый с субъективной его стороны, -это «психические процессы и личностные особенности, поддерживающие результативность, успешность деятельности человека, или его жизненную успешность в целом» $[2$, с. 4]. В конкретно содержательном отношении жизненный ресурс включает «познавательные возможности человека, его интеллект, эмоциональный ресурс, духовный потенциал, ряд личностных возможностей», таких, как «уверенность в себе, стрессоустойчивость, сильная Я-концепция, самоуважение и собственная значимость, самодостаточность, 
активная жизненная установка, социальная смелость, радикализм, ответственность, оптимизм» $[2$, с. 17, 6].

Представление о жизненном ресурсе личности будет, на наш взгляд, недостаточно адекватным, если ограничиться названными выше ее качествами. Так, в содержании духовного потенциала личности необходимо отметить первостепенную значимость для успешной активности ее мировоззренческих (прежде всего смысложизненных и нравственно-этических) качеств, а также степень развития рефлексивности. Именно эти духовные качества личности обусловливают характер и направленность ценностной компоненты ее успехов/успешности.

Немаловажную роль в успехе играет осознание личностью своего призвания и верность ему вопреки разного рода жизненным трудностям и преградам. Это подтверждается не только повседневными наблюдениями, но и исследованиями биографий выдающихся личностей, добившихся соответствующих успехов. Так, на примере исследования жизни и деятельности У. Черчилля Х. Хессе делает обобщающего характера вывод:

Следовать своему призванию [...], никогда не изменять своему призванию - несомненно, важная составляющая личности [...]. Призвание - это знание того, что ты хочешь делать, и убежденность, что ты сможешь это сделать собственными силами [4, с. 38].

Не менее значимы в жизненном ресурсе успешной личности и такие качества, как упорство в стремлении к поставленной жизненной/ профессиональной цели и трудолюбие. Причем принципиально важно и то, что трудолюбие само по себе еще не гарантирует успеха: он приходит прежде всего к тем трудолюбивым (при наличии, конечно, других необходимых его составляющих), кто занимается деятельностью, соответствующей своим способностям и склонностям, по выражению Г. Сковороды, «сродным трудом»:

Это важная отличительная черта поведения успешных людей: сознательно или инстинктивно заниматься тем, что близко, нравится $[4$, c. 38$]$.

Большое значение при этом имеет и необходимый объем практики в том виде деятельности, которой занимается личность, особенно если речь идет о сложной деятельности. Так, М. Гладуэлл констатирует:

Эта мысль - о том, что достижение высшего уровня мастерства в сложных видах деятельности невозможно без определенного объема практики - не раз высказывалась в исследованиях по профессиональной компетенции [1, с. 54]. 
Нельзя обойти вниманием и эмоциональную составляющую в деятельности успешной личности. Без эмоций не бывает успеха не только в искании истины (Ленин), но и в любой сфере человеческой деятельности. Эмоциональный подъем, воодушевление, концентрация всех душевных сил и сосредоточенность на избранном деле, доходящие до самозабвения и самоотверженности, - характерные признаки эмоциональной настроенности личности в процессе движения ее к успеху и достигшей его. Причем речь идет не только о выдающихся личностях, такая эмоциональная настроенность в контексте успеха характерна в той или иной степени для каждой личности.

Хотя жизненный ресурс складывается в основном ко времени достижения личностью своей зрелости, он изменяется в дальнейшем на протяжении всей ее жизнедеятельности. Динамика и направленность этих изменений, обусловленные переменами внутреннего и внешнего по отношению к личности характера, могут быть различными - как позитивными, так и негативными в их влиянии на ее успешность. Если иметь ввиду позитивные изменения, то «в целом возрастание и приумножение жизненных ресурсов личности связано с расширением границ ее опыта, с включением в новые виды деятельности, приносящие актуализацию потенциальных возможностей» $[2$, с. 8], а также, добавим, в не меньшей степени с трансформациями в ее духовном мире и системе жизненных ценностей.

Мысль о том, что жизненный ресурс и шире - вся совокупность индивидуально-личностных качеств человека - являются одной из ключевых составляющих успеха, не нуждается в обосновании в силу своей очевидности. Проблемность состоит в выявлении места и характера связи этой субъективной составляющей с другими, обусловливающими успешность каждой конкретной личности. В философской и научной литературе последнего времени на волне постмодернистского релятивизма и субъективизма, а также под влиянием идеологического клише - «в обществе равных возможностей все зависит только от тебя» - широко распространилось представление об исключительной роли в успехе личности ее индивидуальных качеств. Остальным же составным успеха отводится незначительная, второстепенная роль.

Такой, внешне правдоподобный подход, по своей сути является неглубоким и недиалектичным. Не меньшую значимость в успехе/успешности личности имеют и такие не зависящие от нее факторы, как благоприятные социокультурные условия жизни, воспитание (особенно в семье), образование, микросреда, поддержка и помощь других (прежде всего родных и близких людей) и др. Поэтому обоснованной 
представляется позиция тех, кто, как и М. Гладуэлл, полагает, что

не стоит сводить причины успеха исключительно к личным особенностям. Они не объясняют истинной природы выдающихся [и не только выдающихся, но и любых - B.П., М.X.] достижений [1, с. 20].

Это утверждение вполне справедливо и относительно роли в успешности личности ее врожденных, генетически обусловленных качеств. Хотя аксиомой является признание наличия у индивида таких качеств в виде определенных предпосылок к тем или иным видам деятельности (особенно, в частности, к художественной), столь же обоснованным и доказанным является и то, что названные предпосылки представляют всего лишь задатки к формированию определенных способностей, умений и навыков. Разовьются ли они в соответствующие способности это в значительной степени зависит как от других, уже прижизненно сформированных личностных качеств (воли, целеустремленности, мировоззренческих установок, моральных ориентаций и др.), так и от многих объективных обстоятельств жизнедеятельности личности. И лишь при равенстве всех названных факторов врожденные задатки и особенности индивида дают ему решающее преимущество в успешности. Во многом поэтому далеко не все даже щедро одаренные от природы индивиды достигают успехов, соразмерных своей одаренности, чему немало жизненных подтверждений. В этой связи отнюдь не выглядит преувеличением вывод, что «наше ложное понимание природы успеха во многом объясняется тем чрезмерным значением, которое мы придаем врожденным способностям» [1, с. 54].

Отказ от абсолютизации индивидуально-личностных качеств, включая и генетически обусловленные, важен не только теоретически, но и в жизненно-практическом отношении. Такая позиция предполагает осознанное стремление социума к созданию благоприятных условий для воспитания, образования, развития, совершенствования и разносторонней самореализации всем членам общества как продуманной и оптимально организованной системы. И важно это, исходя не только из гуманных соображений по отношению к личности, но и интересов формирования и развития творческого потенциала самого социума. Абсолютизируя же субъективно-личностную составляющую успеха, «мы напрасно растрачиваем человеческий потенциал. Мы упускаем возможности поднять других на высшие ступеньки успеха» [1, c. 33$]$.

Противоположная позиция - ориентация социума на создание режима наибольшего благоприятствования лишь для одаренных и успе- 
шных - а именно эта тенденция наметилась и приобретает все более выраженный характер в Украине, напротив, ведет к обеднению, а в перспективе к снижению творческого потенциала общества. K тому же такая теоретически уязвимая и практически нерациональная социальная стратегия по сути своей является негуманной и несправедливой по отношению к признанным не одаренными личностям. При этом важно отметить и то, что отсутствуют однозначные критерии одаренности, а также существует проблема объективности и компетентности тех, кто ее определяет (убедительной иллюстрацией этому является известный факт, что ни Ньютон, ни Дарвин, ни Энштейн в школе в числе одаренных не значились).

Среди объективных факторов успеха особое внимание и в жизни, и у исследователей проблемы привлекает случай как независимое от личности стечение обстоятельств, непредвиденное событие, неожиданное вмешательство в ход событий извне и др. Влияние случайного на успех дела издавна подмечено народным сознанием и зафиксировано в языке в таких словах и выражениях, как «везение»/«везучий» (человек), «удача»/«удачливый», «фортуна», «родиться в рубашке»и др. Роль случая в разнообразных его формах и проявлениях, несомненно, велика в успешности личности, что подтверждается жизненными фактами, отмечается исследователями. Так, М. Гладуэлл называет случай в ряду факторов, которые играют очень важную роль в достижении успеха:

Мы будем разрабатывать эту идею,-отмечает он,-оценивая ту роль, которую играют в достижении успеха благоприятные возможности, удачный момент, семья, культурное наследие $[1$, с. 20] (курсив наш-B.П., М.X.).

Х.Хельге, отмечая исключительную роль в успешности личности осознания ею своего призвания, добавляет: «плюс немного удачи» [4, с. 38].

С подобного рода оценками нельзя не согласиться, но принимая их как констатацию факта, необходимо сделать некоторые, на наш взгляд, важные уточнения. Во-первых, роль случая столь же велика и в неудачах личности, поскольку он объективен и присутствует в жизни всех без исключения, как успешных, так и неуспешных. Во-вторых, случай значим в жизни личности не сам по себе, как нечто совершенно автономное, а в контексте всех других факторов, обусловливающих ее активность - как субъективно-личностных, так и объективных. Именно этим можно объяснить, что однопорядковые по своей потенциальной успешности случаи для разных личностей играют неодинаковую 
роль как факторы успеха: одна личность сумеет в полной мере использовать такой случай себе во благо, другая не придаст ему должного значения, третья может вообще не заметить и пройти мимо.

Следовательно, отдавая дань случаю в успешности личности, не следует при этом абсолютизировать его значимость, вырывать из совокупности всех других факторов, обеспечивающих успех.

Успешность личности в обыденном восприятии зачастую связывается с карьерой, особенно в тех видах деятельности, которые предоставляют возможность ей продвигаться в должностном отношении по «служебной лесенке». Такая связь, действительно, существует, но является ли она необходимой и сущностной? Исходя из предлагаемого в данной статье понимания природы успеха как бытийного феномена на поставленный вопрос следует ответить отрицательно. Успешность отнюдь не предполагает в обязательном порядке карьерного роста личности: успешной может быть и такая личность, которая достигает успехов в своей деятельности без изменения служебного положения, в границах тех же самых должностных функций.

Однако и карьерный рост отнюдь не всегда свидетельствует об успешности личности как следствии более полного и результативного самоосуществления и самосовершенствования ее в избранной деятельности. Ведь личность может руководствоваться при этом и весьма далекими от названных мотивами. Поэтому ориентация на достижение карьерного успеха сама по себе, без знания мотивации, не дает оснований как для позитивной, так и негативной оценки личности.

Такой вывод вполне согласуется с научными трактовками понятия карьеры. Как констатируют в данной связи И.Б. Котова и В.А. Новгородская,

общим основанием всех современных научных определений понятия карьеры является стремление человека достичь положения, позволяющего ему наиболее полно удовлетворять свои потребности [2, с. 76].

Тем самым из сути карьеры следует, что именно в содержании мотивов, потребностей, интересов и целей личности и состоит различие между карьерными и карьеристскими ее устремлениями. Если в основе первых лежит стремление личности посредством карьеры к наиболее полной самореализации и самосовершенствованию в органическом единстве с социально значимыми целями и моральными ценностями, то в основе вторых (карьеристских) - стремление к осуществлению своих эгоистических и честолюбивых замыслов, чаще всего при морально индифферентном, а нередко аморальном отношении к выбору 
путей и средств достижения своих целей. В одном случае карьера для личности - средство, в другом - самоцель.

Таким образом, ставя и пытаясь решить вопрос о значимости в личностном успехе различных его составляющих, принципиально важно рассматривать их диалектично: во взаимодействии, не абсолютизируя и не вырывая ни один из них из целостного контекста их взаимосвязи. Только так можно приблизиться к решению сложнейшего уравнения жизненного успеха личности.

Утверждение в «обществе массового потребления» XX столетия потребительства как характеристики всех общественных отношений, образа жизни и системы ценностей, а также дальнейшее углубление в нем индивидуализма вызвали серьезные трансформации и в природе успеха/успешности, восприятии их как личностной и социальной ценности. Важнейшими из этих трансформаций, на наш взгляд, являются следующие:

1. Отрыв личностной ценности успеха от его социальной значимости в жизненных ориентациях и самореализации личности: стремясь к успеху, личность все чаще преследует свои собственные эгоистические гедонистические цели и все реже задумывается об их соотношении с целями и проблемами общества. Все меньше становится тех, кто в своем стремлении к успеху воодушевляется социально значимыми целями и идеалами, высокими моральными ценностями. Непосредственной причиной этого, кроме потребительства, является «рост индивидуализма. . , переход от ограниченного индивидуализма к тотальному» в современном обществе, где «авторитарный капитализм уступает место гедонистическому и либеральному капитализму» и «возникает индивидуализм, освобожденный от последних социальных и моральных ценностей» $[3$, с. $26,27,79]$.

2. В успехе как способе самореализации личности на первый план все определеннее выступает мотив самовыражения, приобретающий у духовно неразвитого индивида-потребителя примитивные формы псевдоиндивидуальности - экстравагантность, эпатажность, экзотичность. И потому, как верно подметил Ж. Липовецки, «чем больше люди стараются выражать себя, тем меньше смысла мы находим в их выражениях» [3, с. 32]. Такой акцент в мотивации успеха фактически элиминирует либо отодвигает на задний план его потенциальные возможности для развития и самосовершенствования личности. 
3. Порожденная сочетанием в позднем капиталистическом обществе потребительства и постмодерна знаковость восприятия индивидом социальных и личностных связей, себя и других не только переносится на успех, но и наиболее ярко проявляется в его понимании и оценке. Это объясняется прежде всего тем, что успех занял одно из ключевых мест в системе потребительских жизненных ценостей (деньги, карьера, вещи, связи, престиж, мода и др.), так как рассматривается социумом и личностью в качестве способа их достижения. В данном контексте успешность воспринимается как знак состоятельности личности, которая либо уже обладает названными ценностями, либо вполне реально может претендовать на них.

4. Знаковый характер успеха неизбежно содержит в себе возможность отрыва его от субъективно-личностных качеств индивида. Успех как знак стоящих за ним потребительских ценностей все чаще становится следствием не самоосуществления личности в избранной деятельности, а внешних по отношению к ней факторов - связей и покровительства, стечения обстоятельств, конъюнктуры рыночных отношений, пронизывающих все сферы жизни общества, «раскрутки» в масс-медиа и др. Тем самым успех все больше превращается из при-знака соответствующих его природе и релизовавшихся в нем личностных качеств индивида в знак «состоятельности» последнего, внутренне с его качествами не связанный. Вследствие этого успех лишается внутренней, личностной укорененности, то есть своего изначального онтологического основания, и легко может приобретать форму искусственно созданного феномена.

Очевидно, что названные здесь трансформации онтологического и аксиологического характера в содержании успеха имеют для перспектив развития, самореализации и самосовершенствования личности негативный смысл и деструктивную направленность. Непосредственной их причиной, а теперь уже и социальным контекстом одновременно, являются потребительство и тотальный индивидуализм как порождение и выражение противоречивости фундаментальных оснований современного постиндустриального общества. 


\section{Литература}

[1] Гладуэлл М. Гении и аутсайдеры: Почему одним все, а другим ничего? - М. : ООО Юнайтед Пресс, 2011.

[2] Котова И.Б., Новгородская В.А. Человек: жизненный и личностный pecypc. - Ростов-н/Д. : Изд-во ГБОУ ДПО РО РИПК и ППРО, 2011.

[3] Липовецки Ж. Эра пустоты. Очерки современного индивидуализма. - СПб. : Владимир Даль, 2001.

[4] Хессе X. Принцип Черчилля: Стань личностью - добьешься успеха. - М. : Текст, 2010.

Надійшла до редакиії 16 липня 2013 р. 